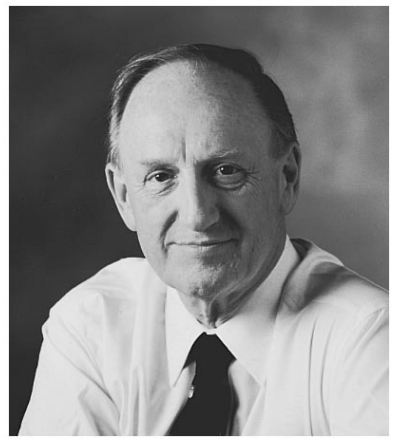

\section{Optical Science and Engineering: An International Discipline}

One of the great pleasures in being your editor is that it keeps me in constant touch with colleagues around the world as we pursue our scholarly and technical work in optical science and engineering. Our family of authors, guest editors, reviewers, and readers is the international team who defines the discipline of optical science and engineering. These thoughts lead me to the International Commission for Optics (ICO), which I last wrote about in this column back in October 1995. This organization is of considerable interest to me since the next ICO Congress, ICO 18, will be held in San Francisco in August of 1999. The planning work has already started and SPIE-The International Society for Optical Engineering has been selected as the conference managers for this congress.

The Secretary General of the ICO Bureau, Pierre Chaval, has prepared and distributed a write-up entitled "What is ICO?" With his permission it is reproduced here as a service to our international readership.

\section{What is ICO?}

The International Commission for Optics was created in 1947. It is an Affiliated Commission of the International Union of Pure and Applied Physics (IUPAP), and as such part of the ICSU family (ICSU is the International Council of Scientific Unions). As is clear from its name, its objective is to contribute, on an international basis, to the progress and diffusion of knowledge in optics.

The commission has members representing identified optics communities. A member adheres to ICO through its Territorial Committee for Optics. At present, the number of members is 44 . The governing body of ICO is its General Meeting, usually held every three years during an ICO Congress that also includes an international conference on optics. Between General Meetings, a Bureau is responsible for the conduct of the Commission. The $\mathrm{Bu}-$ reau consists of the President, the Past-President, the Sec- retary General and the Associate Secretary, the Treasurer, and eight Vice-Presidents, of whom at least two are from industry.

In order to serve and be representative of the optics community worldwide, ICO maintains contacts with its Members and with optical scientists in all countries and welcomes all new contacts. Together with the other societies involved, it contributes to the coordination of international activities in optics such as in particular scientific meetings. The latest ICO Congress, ICO 17, was held in Taejon, Korea, in August 1996 and attracted 538 scientists from 33 countries. ICO 18 will take place in San Francisco, California, August 2-6, 1999. In addition to its Congresses, ICO initiates international topical meetings, and acts as a cosponsor for a number of international scientific meetings organised by other bodies. In 1996 and 1997, this is the case of the following events: OC'96 Intl. Topical Meetg. on Optics in Computing, Sendai, Japan, 21-25 April 1996; OWLS IV, Intl. Conf. on Optics within the Life Sciences, Münster, FRG, 9-13 July 1996; Intl. Conf. on Holography and Optical Information Processing, Nanjing, China, 26-28 August 1996; Intl. Workshop on Interferometry, Wako, Japan, 27-29 August 1996; Photonics'96, Madras, India, 10-14 Dec. 1996; the 10th Meetg. on Optical Engineering in Israel, Jerusalem, 9-13 February 1997; OC'97, Intl. Topical Meetg. on Optics in Computing, Lake Tahoe, NV, USA, 16-21 March 1997; ECIO'97, Eur. Conf. on Integrated Optics, Stockholm, 2-4 April 1997; Intl. Workshop on Adaptive Optics for Industry and Medicine, Sharura, Russia, 9-13 June 1997; EOS Topical Meetg. on Diffractive Optics, Savonlinna, Finland, 7-9 July 1997; Education and Training in Optics, ICO Fiftieth Anniversary Meetg., Delft, the Netherlands, 19-22 August 1997; OIST'97, Optical Information Sc. and Technol, Moscow, 26-30 August 1997; RomOpto'97, Bucharest, Romania, 9-12 Sept. 1997.

ICO has established a Committee for the Regional Development of Optics and has contacts with the International Centre for Theoretical Physics, ICTP, Trieste, Italy, in order to find new ways to provide help to optical scientists and engineers in developing countries, in particular through the exchange of information and through the joint organisation of schools. Under a Proceedings Donation 
programme, some libraries in developing countries can receive copies of the proceedings of Conferences with ICO participation. Schools with ICO participation are of a typical duration two or three weeks, for the main benefit of optical scientists and engineers in non-industrialised countries. The contribution of ICO is mainly in the form of support in establishing the programme and finding the appropriate instructors. In 1995 and 1996, ICO participated in the following schools: 2nd ICTP/ICO Winter College on Optics, Trieste, Italy, February 21-March 10, 1995; 4th Intl. Workshop on the Physics and Modern Application of Lasers, Khartoum, Sudan, 6-14 January 1996.

A Newsletter covering ICO activities is published four times a year; it is included in the magazine of the Optical Society of America, "Optics and Photonics News,'” and in the magazine of the SPIE, "Optical Engineering Reports," and is sent to all ICO members in a quantity sufficient to allow broad distribution within their territory. Additional copies may be obtained from the ICO secretariat in paper or electronic mail form.

ICO has established two international awards:

- The ICO Prize is awarded annually to a person who has made a noteworthy contribution to optics, published or submitted before he or she has reached the age of 40 . The recipient is selected by the ICO Prize Committee. It consists of a citation, a sum of US $\$ 1000$, and the Ernst Abbe medal, donated by the Carl Zeiss Foundation.

- The Galileo Galilei Award is awarded annually to a person who has made outstanding contributions to the field of optics under comparatively unfavourable circumstances. It consists of the Galileo Galilei Medal, donated by the Societa Italiana de Optica e Fotonica, financial support for participation in the next ICO General Meeting, and measures to favour the future activities of the award winner.

ICO has established a Travelling Lecturer Programme to promote lectures on modern aspects of optics by scientists of international reputation with good lecturing skills. The program is aimed more particularly at developing nations, even though it is not necessarily restricted to them. As a rule it is expected that the lecturer's local expenses will be met by the host institution and that ICO's contribution will be toward travel costs. ICO has established an ICO Fellowship programme primarily intended for optical scientists and engineers from non-industrialised countries. The goal is to provide the initial means for establishing a long-term relationship between a young scientist or engineer in a non-industrialised country and an internationally renowned research group in another country. The Fellowship is intended to fund a short visit, with a goal of establishing a joint programme of research, teaching or training that would be funded from other sources. Funds donated to ICO by the Rank Prize Fund, a UK based foundation, have provided means to initiate the ICO Fellowship programme for visits to the UK.

ICO has launched a series of books, entitled "Trends in Optics,' which is planned to grow by one volume every three years. These books provide an authoritative overview of research that is underway in the field of optics throughout the world. The articles, which are suitable for the specialist and non-specialist alike, provide general, readable overviews of many different aspects of optical science and engineering. The royalties typically paid to the editor and the authors are instead paid to ICO to provide additional funds to such activities as the Travelling Lecturer Programme. The third volume appeared in August 1996.

In addition to the above activities, ICO has established a Committee on Standards and a Long Range Planning Committee. The ICO President for the period 1996-1999 is Professor Toshimitsu Asakura, Institute for Electronic Science, University of Hokkaido, Sapporo 060, Japan. Further information, including information on ICO membership and details on all the above mentioned ICO programmes, can be obtained from the ICO Secretariat, BP 147, 91403 Orsay cedex, France, telephone +33 1-69 35 $87 \quad 41$, fax +33 $1-69 \quad 35 \quad 87 \quad 00$, e-mail Pierre.Chavel@iota.u-psud.fr. Meetings issues are handled by the Associate Secretary, Prof. Ari T. Friberg, University of Joensuu, PO Box 111, FIN 80101 Joensuu, Finland, phone +358 132513213 , fax +358 13251 3290, e-mail ari.friberg@joensuu.fi.

\section{Editor's Anecdote}

My nephew in England sent me a beer mat from his restaurant "The Pot Bellied Pig" that had a quote on it ascribed to Claude Debussy. I reproduce it below.

\footnotetext{
"MUSIC IS THE ARITHMETIC OF SOUNDS AS OPTICS IS THE GEOMETRY OF LIGHT',
} 